\title{
EDITORIAL
}

\section{Para tempos de resistências político-midiáticas}

Nós, da RuMoRes, revista científica dedicada aos estudos de comunicação, linguagem e mídias, colocamo-nos juntos na defesa geral da educação, como via de transformação social; na produção científica, que representamos ao longo das edições publicadas; bem como na abertura para a pluralidade de vozes necessária a esse campo, no sentido da inclusão e da partilha, assumindo o essencial enriquecimento do debate. Considerando nossa filiação com o trabalho no campo da linguagem, entendemos que essa construção partilhada do conhecimento se revela nas conjunções políticas e estéticas a um só tempo, que esperamos ver contempladas na variedade da edição apresentada:

\begin{abstract}
A partilha do sensível faz ver quem pode tomar parte no comum em função daquilo que faz, do tempo e do espaço em que essa atividade se exerce. Assim, ter esta ou aquela "ocupação" define competências ou incompetências para o comum. Define o fato de ser ou não visível num espaço comum, dotado de uma palavra comum etc. Existe, portanto, na base da política, uma "estética". ${ }^{1}$
\end{abstract}

Assim, na 27a edição da revista, publicamos o dossiê "Resistências político-midiáticas" e um corpo de artigos que abordam questões da estética das mídias, buscando a variedade de suportes como forma de investigação abrangente sobre suas estratégias narrativas. Os textos selecionados trabalham formas de protagonismo dissidente, o endereçamento de relatos coletivos, uma problematização de narrativas dominantes e tentativas de silenciamento. De maneira positivada, implicam questões que são parte da agenda do grande 
campo das humanidades e que têm impulsionado viradas teóricas, das quais especialmente nomeamos: a luta antirracista, a luta democrática, a luta pelas liberdades de gênero e um olhar local para as desigualdades. Tais discursos muitas vezes não aparecem nomeados, mas a tomada dos objetos empíricos revela esse compromisso social e uma abordagem que entendemos como inescapavelmente mobilizadora.

Nossos temas ganham perspectiva tanto no sentido estrito da política, de um lugar de representatividade dentro de estruturas democráticas de governo, quanto na sua dimensão mais ampla, que se liga à demanda dos grupos sociais e das populações a serem representadas e que protagonizam as estéticas dessas mesmas representações. A mobilização que pleiteamos significa, assim, um chamado a um tempo político e estético que conecta ações coletivas com outras, relacionando o individual ao social.

Se os problemas de pesquisa estão definitivamente atravessados pela agenda mobilizadora, pede-se também um novo endereçamento da apropriação teórica como identificação e manutenção de um lugar de saber. Questiona-se metacriticamente o lugar mesmo de onde se fala, procurando com isso anunciar qual é seu movimento: autoral, metodológico, subjetivo. A análise teórica se compromete, assim, com os sujeitos, começando por aqueles que podem falar e que anunciam sua pesquisa para, em seguida, ampliar seu campo de fala a partir das próprias análises, estabelecendo uma visão crítica:

Crítica é sempre crítica de alguma prática institucionalizada, um discurso, uma episteme, uma instituição. Sendo assim, ela perde seu caráter básico no momento em que, abstraída de sua operação constitutiva, é posta em isolado como prática puramente generalizável. Mas disto não se segue que nenhuma generalização seja possível, ou ainda, que nos atolamos em particularismos. Ao contrário, o terreno em que aqui pisamos, é de uma generalidade restrita que beira o filosófico, mas que deve, se seu intento é o de permanecer crítico, guardar distância desse mesmo empreendimento. ${ }^{2}$ 
Mais uma vez, entendemos que a formação de um objeto a ser estudado também está marcada por uma estética e por um olhar. Se a teoria é metacrítica, o olhar pode ser proposto como metassistêmico. Assim, metacriticamente e metassitemicamente, voltamo-nos de maneira mediada para os objetos de nossas pesquisas e colocamo-nos entre o referente (suas materialidades, seus suportes) e a possível magia de aspectos concretos de nossos corpora. Entre a pretensão ampla da teoria e a análise particular dos objetos pontuais, em sua capilaridade, compomos possibilidades de deslocamento sempre singulares, numa possível aproximação dialógica da academia com a sociedade para a qual ela se reporta.

O dossiê "Resistências político-midiáticas" é aberto com uma revisão de conceitos debordianos, em contraste com o pensamento de Hannah Arendt, feita por Claudio Novaes Pinto Coelho em "Política, poder e comunicação em Debord e Arendt", na busca pela potência dessas noções para uma transformação revolucionária da sociedade capitalista. Passando para a arte cinematográfica e pensando as possibilidades de construção de um relato da ordem do coletivo nas telas, Henri Arraes Gervaiseau analisa Lost, lost, lost, de Jonas Mekas, em "Travessia do herói e pertencimento à ordem do coletivo", para discutir o processo de construção do relato, e dar conta de vivências afetivas e sócio-históricas evocadas pelo narrador-diretor. A história vai para as ruas no texto "Resistência e dissonância nas narrativas em disputa: a voz da mídia e a voz dos movimentos de ocupação de 2016", de Hila Rodrigues e Juarez Rocha Guimarães. O artigo analisa a produção midiática e dos segmentos juvenis durante os movimentos de ocupação nas escolas e universidades no segundo semestre de 2016, problematizadores da narrativa dominante inaugurada pelos meios de comunicação televisivos e resistentes às estratégias de silenciamento.

Formas de protagonismos dissidentes e uma releitura do que é poder são buscadas por Bruno Navarini Rosa e José Carlos Marques, em "Futebol, povo e poder: uma análise de Garrincha, alegria do povo e Isto é Pelé a partir de seus contextos históricos de produção", para entender a relação entre futebol, povo 
e poder como apoio ou resistência aos governos atuantes no período. No campo das discussões queer, Guilherme Maia e Everaldo Asevedo, em "Música, afeto e política dos corpos no New Queer Cinema de Karim Aïnouz", buscam esse lugar de visibilidade na análise dos projetos musicais de Madame Satã e Praia do Futuro, dois filmes com protagonistas gays, e observam os ideais de representação de personagens homossexuais defendidos por esse cinema. Em "Bela, recatada e do bar: memes de internet, política e gênero", Rayza Sarmento e Viktor Chagas recuperam as reações nos sites de redes sociais à reportagem publicada pela revista Veja, em abril de 2016, para tentar compreender, no protagonismo das mulheres nas redes, como as internautas operacionalizaram a crítica ironizando os adjetivos empregados para qualificar Marcela Temer.

Os demais artigos da edição apresentam uma entrada para investigações em diferentes mídias e refletem sobre suas diferentes estéticas. Em "Miriam Hansen e as concepções da Escola de Frankfurt sobre o cinema", Otávio Daros realiza uma pesquisa bibliográfica dos trabalhos de Miriam Hansen para organizar as principais diferenças entre pensadores frankfurtianos e entender o cinema como sintoma da realidade urbano-industrial. Em "A publicidade sem caráter e a estética do velamento", João Anzanello Carrascoza trabalha a estética na publicidade por meio das reflexões de Byung-Chul Han na obra $A$ salvação do belo (2019), visando pensar as mudanças resultantes da expansão tecnológica das últimas décadas. Genio de Paulo Alves Nascimento e Andre de Paula Eduardo, em "Joaquim, Vazante e $O$ nó do diabo: a herança da escravidão (re)vista pelo cinema brasileiro", analisam três filmes para entender a reiteração do assunto da escravidão e sua relação com o contexto político brasileiro atual.

Arthur Carlos Franco Oliveira e Hertz Wendel de Camargo, em "Narrativas audiovisuais e mitologia: a quaternidade mítica aplicada aos animes", considerando a ritualização de arquétipos, examinam Sakura Card Captors, Code Geass e The Seven Deadly Sins, buscando uma estrutura que movimenta suas narrativas. Em "Anacronismo, choque e verossimilhança: a ficção científica na telenovela O tempo não para", no cruzamento entre ficção científica e telenovela, Marcel Vieira 
Barreto Silva e Esmejoano Lincol da Silva de França analisam a novela exibida pela TV Globo. Por meio de personagens de ontem questionando os personagens de amanhã, interpretam as mudanças sociais ocorridas no país em mais de 130 anos.

Pensando as mídias que tradicionalmente transitam pelo relato factual, Marcos Vinicius Meigre e Silva, em "O acontecimento João de Deus e os enquadramentos na mídia televisiva", analisa o programa Fantástico, da TV Globo, sobre os posicionamentos assumidos pelos sujeitos em torno das denúncias contra João de Deus, considerando os papéis sociais "pai", "médium" e "criminoso". Luana Viana pensa as possibilidades de um radiojornalismo narrativo, analisando um dos episódios do podcast Projeto Humanos no texto "O uso do storytelling no radiojornalismo narrativo: um debate inicial para podcasting". Em "O Grupo Globo e as restrições à autonomia da Rádio CBN", Patrícia Maurício e Creso Soares Junior recuperam a trajetória da Central Brasileira de Notícias (CBN) na passagem de uma relativa autonomia editorial para a tutela do Grupo Globo, entrevistando profissionais que trabalharam em cargos de comando na emissora.

Como fechamento da edição, a narrativa policial é tratada na forma do romance. Taynara Leszczynski e Maria Salete Borba, em "Entre enigmas e possibilidades: configurações detetivescas nos romances As iniciais, de Bernardo Carvalho, e O silêncio da chuva, de Luiz Alfredo Garcia-Roza", investigam as possibilidades do romance policial contemporâneo, tomando por base dois romances brasileiros e considerando que, apesar de manterem muitas configurações modernas, sua estrutura não é fixa ou linear.

Em um semestre marcado pelo momento dramático causado pela pandemia da Covid19, que se alastra pelo mundo e atinge todos os países de modo brutal, vivemos no Brasil também uma de suas maiores crises políticas, em que os campos da educação, da ciência, da cultura e das artes - sem contar o da saúde pública - vêm sendo duramente atacados. Em tempos de distanciamento social e isolamento, os desafios que se colocam à universidade pública e à pesquisa nela desenvolvida são ainda maiores. 
Nesse cenário atípico, agradecemos ainda com mais força a todos e todas que colaboraram para a publicação de mais uma edição de RuMoRes e, especialmente, aos nossos leitores e leitoras, onde quer que se encontrem nesse mundo virtual. Que em breve possamos estar novamente juntos e cada vez mais fortalecidos para o enfrentamento dessas transformações.

MidiAto - Grupo de Estudos de Linguagem: Práticas Midiáticas julho de 2020 